\title{
Erratum to: Can the left hepatic vein always be safely selectively clamped during hepatectomy? The contribution of anatomy
}

Frédérique Peschaud - Anais Laforest •

Marc-Antoine Allard • Mostafa El Hajjam •

Bernard Nordlinger

Published online: 31 December 2009

(C) Springer-Verlag 2009

Erratum to: Surg Radiol Anat (2009) 31:657-663

DOI 10.1007/s00276-009-0495-x

Unfortunately, the first and last names of the authors have been wrongly published. The correct author names are as follows:

Frédérique Peschaud, Anais Laforest, Marc-Antoine Allard, Mostafa El Hajjam, Bernard Nordlinger

The online version of the original article can be found under doi:10.1007/s00276-009-0495-x.

F. Peschaud $(\varangle) \cdot$ A. Laforest · M.-A. Allard · B. Nordlinger

Department of Surgery, Hospital Ambroise Paré,

9 Avenue Charles de Gaulle, 92100 Boulogne, France

e-mail: frederique.peschaud@apr.ap-hop-paris.fr

F. Peschaud

Département of Anatomy, Paris-Ile de France Ouest Versailles,

Saint Quentin en Yvelines, Versailles, France

F. Peschaud · B. Nordlinger

Université Versailles Saint Quentin en Yvelines,

78000 Versailles, France

\section{A. Laforest · M.-A. Allard}

Institut of Anatomy, Centre universitaire des Saint-Pères

Université Paris V René Descartes, Paris, France

M. E. Hajjam

Department of Radiology, Hospital Ambroise Paré,

Boulogne, France 